\title{
Wound Ballistics: Contemporary and Future Research
}

\author{
Lieutenant Colonel J M Ryan*† \\ FRCS, RAMC
}

Senior Lecturer in Military Surgery

Graham J Cooper*

PhD

Senior Lecturer in Trauma Science and Head of Trauma Section

\section{Dr Robert L Maynard*}

$\mathrm{BSc}, \mathrm{MB}, \mathrm{BCh}$

Senior Lecturer in Clinical Pharmacology and Superintendent Medical Division

*The Ministry of Defence, Chemical Defence Establishment, Porton Down, Salisbury, Wilts. SP4 OJQ

tAlso Consultant Surgeon - Princess Alexandra Hospital, RAF Wroughton, Swindon, Wilts.

SUMMARY: Wound ballistics research has contributed much to the understanding of the pathophysiology of missile injury that now exists. From this store of knowledge treatment regimes have evolved which have greatly improved the lot of the soldier wounded in war. However, research must keep pace with changes that are taking place in weapons research and development so that the particular needs of the Army Medical Services on a future battlefield can be met. The differing needs of civilian and military medical services are highlighted. The marked differences that exist between the missile wound seen and treated in a late twentieth century hospital and the wounds likely to be encountered on the modern battlefield are enumerated and discussed.

\section{Introduction}

A Medical Officer attempting to review the wound ballistics literature which has appeared over the last 10 years would be faced with a bewildering mountain of papers from a large number of research centres. Much of the research has been conducted by non-medical

scientists, including engineers, physicists, biochemists and weapon technologists. The consequence of this is that many papers are unfamiliar in presentation and technical content to medical readers. This has led to misunderstanding and misinterpretation by some, particularly surgeons, as a critical review of ballistics articles in the surgical journals reveals ${ }^{1,2}$.

The aim of this paper is to review the more important and controversial papers and to explore, examine and explain, in context, the views stated and conclusions drawn. This would seem to be of particular importance at the present time in view of some recent publications in the world literature. These, at first sight at least, appear to contest the orthodox in the wound ballistics area that finds acceptance in this country and in the Army Medical Services in particular ${ }^{3,4,5}$.

In addition the opportunity is taken to suggest where future ballistics research pertinent to the requirements of the Army Medical Services should be directed.

\section{Historical}

\section{Early Observations}

Wound ballistics research is not new. With the advent of an efficient handgun in the middle of the sixteenth century, penetrating bullet wounds became a commor feature of European battlefields and became the objec? of study by the military surgeons of the day. These early pioneers have left us a rich written legacy, much of it stilg relevant. Ambroise Paré spent over 30 years in the French Army and wrote extensively on the subject of wounds caused by firearms. His works, translated intơ English by Thomas Johnson, remained a standard reference work on treatment for a century following his death $^{6}$. In Great Britain, over a century later, John Hunter published his celebrated treatise on gunshot wounds ${ }^{7}$. Like Paré's work it became a bench mark for military surgeons.

Research in the nineteenth century:

Modern ballistics came into being in the middle of the nineteenth century with the recognition of wounds caused by high velocity bullets from rifled muskets. The pattern of injury in such wounds was widely reported in many countries $8,9,10,11,12$.

There followed the first controlled experiments on injuries produced by high-velocity projectiles ${ }^{13}$. In the United Kingdom a series of experiments by Horsley using clay, soap and anaesthetised dogs demonstrated lateral disturbance of tissues following the passage of high-velocity missiles ${ }^{14}$. He concluded that wounding power was a consequence of energy transfer to the particles of tissue which are "hurried forward" enlarging the wound track. In 1897 Stevenson, the Professor of Military Surgery at Netley conducted a series of 
experiments firing high-velocity missiles through open and closed lead cans filled with water. He demonstrated for the first time that the lateral displacement of tissue, in this case water, followed the passage of the missile ${ }^{15}$. This phenomenon of energy transfer associated with displacement of tissue was also noted during experiments conducted in the United States and was called cavitation by Woodruff ${ }^{16}$.

\section{The Twentieth Century:}

Little further progress was made until, using clay models, Callender and French clearly demonstrated the cavitation process and showed the importance of retardation in the energy transfer/wound severity equation. They examined the effects of velocity, missile geometry, mass and stability and they propounded certain definitions and formulae in an attempt to make the subject understandable to the Military Surgeon ${ }^{17}$. Using spark photography, Zuckerman and his colleagues showed that cavitation would also occur in an elastic tissue simulant ${ }^{18}$. With the advent of high-speed cinematrography Zuckerman's work was carried further by Harvey and his colleagues at Princeton. They confirmed the relationship of cavitation effect to missile velocity and reiterated the kinetic energy equations propounded by Callender and French ${ }^{19}$.

\section{Contemporary Research}

Experimental work using cadavers, clay and elastic tissue simulants such as $20 \%$ gelatin are limited in their scope. It was not until 1963 that the detailed pathophysiology of missile wounds was studied using a standardised penetrating thigh wound model in anaesthetised sheep ${ }^{20}$. This work demonstrated a relationship between the extent of muscle damage and cavitation, a phenomenon already known to be related to velocity. Three distinct areas in a penetrating missile wound of muscle were defined; there was a central nonviable area of tissue directly in the path of the missile which was lacerated and crushed, an adjoining area of damaged tissues as demonstrated by abnormal histological staining, and, surrounding this, was an area where there was lack of filling of small blood vessels and extravasation of blood.

The liability of these damaged areas to infection by anaerobic organisms was recognised. Owen-Smith and Matheson went further and demonstrated experimentally that contamination of damaged muscle with spores of Clostridium welchii inevitably led to gas gangrene $^{21}$.

They showed that the development of gas gangrene could be prevented by early excision of the damaged muscle but not by fasciotomy alone. Owen-Smith went on later to demonstrate the beneficial effect of antibiotics in preventing such infection even when surgery was delayed. He found that intramuscular penicillin and high dose oral tetracycline, administered early, were completely effective in the prophylaxis of gas gangrene in high velocity bullet wounds of $D$ muscle $^{22}$. That contamination, studied experimentally by Owen-Smith and Matheson, occurs in practice has been confirmed by numerous workers ${ }^{20,23,24,25,26}$. It has been shown that muscle damage beyond the limits of the permanent wound track favours the growth of numerouso organisms, particularly $C 1$ tetani and $C 1$ welchit. The pathology of wounds other than in muscle was studied by $\mathrm{Scott}^{27}$. Although macroscopic changes in brain and liver had been described as early as $1957^{28}$ it was not untilo 1976, following Scott's experiments on liver and brain,흐 that there was much understanding of the cavitation $\frac{\bar{\rho}}{\bar{Q}}$ effect on these organs.

His conclusions were that Hopkinson's earlierg histological description of the muscle wound was? applicable to the liver. He noted also that altered cello viability beyond the area of cavitation could extend to $\overrightarrow{\vec{\omega}}$ the liver capsule. Skull injury following the passage of a high-velocity missile was studied using dried human skulls (some of which were empty and some of which were filled with $20 \%$ gelatin and covered either with? chamois leather or a helmet). Scott clearly $\vec{\omega}$ demonstrated the marked increase in severity of fracture in the skulls filled with gelatin. Using anaesthetised animals he went on to demonstrate macroscopically a a histologically the damage presumably caused by을 cavitation in the mammalian brain ${ }^{27}$.

In a further series of experiments Scott looked at the effect of altering impact velocity in wounds to pig colo\$. Using a deformable soft pointed hunting bullet (Horn $\$$ $0.22^{\prime \prime}$ ) and by varying the charge he showed the possibe increase in severity of injury that may occur as the $\infty$ impact velocity changes from low to high-velocity. H. experiments on the effect of striking bone using Sovig;; American and NATO assault rifle bullets demonstratẹ the great increase in wound severity that occurs. Slivers of bone, behaving as secondary missiles, are accelerated through surrounding tissues. A complimentary study $\frac{\mathscr{Q}}{\square}$ looked at the effect of bullet break up or fragmentation $\underset{F}{\overrightarrow{1}}$ on wounding, and again he clearly demonstrated an increase in wound severity, increasing with bullet mass $^{27}$.

Concurrent with Scott's work in the United Kingdom, Berlin and his colleagues in Sweden were carrying out extensive experiments aimed at the question of correlating damage done at time of injury to the transfer of kinetic energy ${ }^{29,30}$. Using pigs of Swedish landrace stock and carefully standardised methods, they produced a large series of experimental wounds produced by high velocity missiles. Seven weapon types were used giving a wide variation in bullet calibreo $(5.56 \mathrm{~mm}$ up to $9.00 \mathrm{~mm})$ and velocity $(607 \mathrm{~m} / \mathrm{s}$ up to $911 \mathrm{~m} / \mathrm{s}$ ). The results of their work were in keeping witho the work being done in the United Kingdom.

They considered that most of the destructive effects of high-velocity assault rifle bullets are due to the high velocity of the projectiles, the inherent instability of o these missiles in tissue, and to the deformation and 
break up of these missiles in tissue. When a bullet entered a medium of higher density than air, changes in effect occurred. Firstly, spin stabilisation was overwhelmed in a high density material allowing the missile to commence tumbling and thus to increase its transfer energy to the tissues. Then a temporary cavity was formed behind the projectile because of the deposition of energy. The rate of energy transfer was viewed as an intergral of the retarding forces at work over the missile's length of travel.

Comments were made on shock waves. It was pointed out that strong shock waves occur in air when the velocity of the missile reaches supersonic speed and that these increase in amplitude with increasing velocity. However, acoustic or stress waves did not cause appreciable movement of tissue and they therefore concluded that these waves play only a minor role in wounding by penetrating missiles. Their comments on fragmentation were in agreement with Scott's findings. It was noted that retarding forces are greatly increased (up to 20 times) when a missile tumbles as compared to when it retains nose-on stability. These forces were further increased if the missile fragmented because the fragments usually stopped in the tissue thus yielding all their available kinetic energy.

Berlin and his colleagues produced a large number of wounds caused by a range of weapons and ammunition. The wounds produced were excised and a correlation was demonstrated between the amount of debrided tissue (MD) and the energy transferred $(\triangle E)$. It is important to point out that this correlation is accurate only for injuries to soft tissues in limbs using nonfragmenting, non-yawing spheres. Calculations were improved by including a track length term in the equation. MD could then be expressed as amounts of debrided tissue per millimetre of track length. It was found that the pattern of energy deposition along the wound track, expressed in percentage terms, differed from projectile to projectile. Conclusions from Berlin's second study ${ }^{29}$ published in 1977 elaborated on their carlier findings, and it was stated that energy transfer decides the character and severity of missile damage.

Energy transfer from a missile was principally governed by changes in its orientation along the wound track. It was further influenced by deformation and fragmentation of the missile. From the foregoing it was concluded that, although velocity is important as a determinant of available energy, tumbling and fragmentation determine the transfer to the tissues. It was felt that the current criteria for determining the nonviability of muscle were crude and inexact and might lead to the excision of potentially viable tissue. It was also felt that no one has yet been able to pinpoint the ideal time interval between wounding and commencement of surgical excision ${ }^{29}$.

At the time of the reporting of these experiments by Scott in the United Kingdom and Berlin in Sweden, a clearer picture of wound ballistics emerged. There was now a better understanding of the pathophysiology of $D$ wounding, particularly so called high-velocity wounding. A new and more descriptive term entered the language of wound ballistics, "high-energy transfer wounding", recognising that the cavitation produced by a missile is more a feature of its energy transfer than of its impact velocity. This more accurate term reflected the better understanding of these wounds that now existed. High-velocity missiles, it was realised, given certain circumstances would produce a high-energy wound. It was equally realised that under different circumstances they might not. Although the importance of velocity is not in question, other factors also play a vital role in energy transfer and therefore in wounding power - orientation of the missile, fragmentation and deformation, tissue track characteristics and, not least, the mass of the missile $e^{17,23,27,29}$.

A number of problems remained. There was as yet no clear and accurate guide for distinguishing with certainty damaged but recoverable muscle from non-viable muscle and this still meant that surgeons might excise viable muscle. Although the problems of tetanus and gas gangrene had been extensively studied, there was little understanding of the interaction between damaged muscle and bacterial contaminants. Owen-Smit $\mathrm{N}$ showed clearly the beneficial effects of antibiotics if 윽 prophylaxis of gas gangrene ${ }^{22}$, but their role in generat contamination and infection had not been established.

Dahlgren, working with Berlin, Rybeck and othe studied the bacteriological findings in standardise wounds at one hour, six hours and twelve hours aft@ wounding ${ }^{31}$. No antibiotics were used. They identified reversibly damaged cells in the border zone betwee obviously dead tissue and obviously healthy tissue, had already been reported by Hopkinson and Scott ${ }^{23}$, and they were able to demonstrate that these cells were adversely affected by even small amounts of mixed bacteria, including strains not normally considered pathogenic.

These sparse mixed contaminants, it was felt, seemed to be able to create conditions necessary for the development of clinical infection if treatment was delayed. They noted that the extent of non-viable muscle increased with time, particularly within the first six hours after wounding, and concluded that, using current operative technique, it would be possible to prevent, or at least control, infection if surgery was undertaken within six hours. Beyond that time bacteria would have entered the phase of rapid growth and invasion, and surgery alone would be insufficient. They also concluded that current debridement techniques would appear to leave contaminated tissues in situ. Positive cultures were found in $99 \%$ (66\% infection, $33 \%$ contaminants) of swabs taken from post excision, apparently healthy margins in the 12 hour group.

Caution is necessary in interpreting the work of Dahlgren and his colleagues. A semiquantitative $\Omega$ evaluation of the total number of bacteria was done and 
terms such as "small", "moderate" and "heavy" were used to describe bacterial growth. The finding of a "heavy" growth of a single strain was taken to indicate infection. "Small" or "moderate" growth of one or more strains was assumed to indicate that growth in situ had not taken place and a diagnosis of contamination was made. There is no universal definition of these terms and this makes clear deductions from this work difficult.

There followed a trial attempting to determine the influence of early antibiotic administration coupled to delayed surgery ${ }^{32}$. The aim of early antibiotic therapy was to destroy the mixed contaminating flora seen early following wounding, and assumed to be the precursor of a later significant infection by a single pathogenic strain. As they had earlier identified these mixed sparse organisms as being sensitive to benzyl penicillin, this was the antibiotic of choice. Their results indicated that the expected growth of a pathogenic strain (itself usually penicillin resistant) following a twelve hour delay, was inhibited by giving penicillin one hour after wounding. Indeed, giving antibiotics early seemed to produce a similar result to that seen in the group operated on within six hours. It was also noted that, in addition to this treatment preventing infection in the delayed surgery group, the amount of tissue judged to be nonviable was markedly reduced compared to that in the delayed group in the previous study. This finding obviously raised the question of whether penicillin itself had a direct effect on injured cells or whether it was its effect on bacterial contaminants that allowed injured cells to recover.

An important concluding point made in this paper was that these early trials and results should not lead to the suggestion that treatment protocols should be altered. It was emphasised that devitalised tissue must always be removed before healing can take place. At best, the available evidence indicated that early antibiotic treatment may buy time and reduce the quantity of devitalised tissue which would usually be found after a delay in surgical treatment.

In the United States these studies have been critically appraised in various journals. Some of these critical papers appear, at first glance, to comment adversely on certain aspects of the experimental design and on the conclusions drawn. Two of these require close scrutiny ${ }^{3}$. Lindsey's dramatic editorial ${ }^{5}$ entitled "The Idolatry of Velocity, or Lies, Damn Lies, and Ballistics" is interesting in that he reiterates much of what is already agreed, certainly in the United Kingdom and Sweden. He reminds readers that $K E=1 / 2 M V^{2}$ is the "kinetic energy formula" and not the formula for wounding. He argues that velocity receives too much attention in energy equations and he reminds us of the importance of mass. Few would disagree. Most experimental and field surgical evidence clearly indicates that velocity has an important but not exclusive role in the determining of wound severity. Lindsey's statement that cavitation is nothing more than mechanical displacement of tissue and that there is no indication to debride a temporary $D$ cavity is, however, much more contentious. In the first place, few surgeons speak of debriding a temporary cavity. A temporary cavity is a space, created transiently $\frac{7}{0}$ by the movement of tissue; the cavity exists for only a very short time and, after its collapse, a permanent 0 wound track remains. It is this wound track and the surrounding tissues that concern the surgeon, and these may certainly require excision depending on circumstances as discussed earlier in this review.

Fackler's major review paper $^{3}$, recently published, is, 응 on the surface, equally contentious. He argues strongly $\frac{\bar{s}}{\bar{D}}$ that sonic pressure waves do not cause injury, and cites $\mathbb{D}$ evidence from papers by Harvey and, more recently, from lithotripsy centres in support of this view. Most कs workers in Europe, such as Scott and Berlin, are largely $\vec{O}$ in agreement with this and have stated that stress or $\overrightarrow{\vec{H}}$ sonic waves are not clinically important in injury produced by penetrating missiles. They do, however, have a significant role in non-penetrating impact ${ }^{33}$. With regard to his discussion on cavitation he is right to point out the error of stating that "cavitation requires $\vec{\omega}$ extensive debridement of tissue ${ }^{34}$. It would be more $\vec{b}$ appropriate to say that cavitation may produce tissue ch damage which may require wound excision. Lile Lindsey he perhaps understates the possible importane 0 of cavitation when he describes it as "stretch" $\mathbb{0}-$ "localised blunt trauma". Research shows that, give the right conditions, it may be devastating ${ }^{27}$. The role \&f cavitation in the destruction of tissue is determine principally by the characteristics of the organ in whigh the cavitation occurs. He is also of the view that the rode of fragmentation is underestimated, although Sco,$\infty$ Berlin and others had recognised and reported fragmentation in the 1970's.

Fackler points out certain fallacies and misunderstandings that appear to exist as evidenced by some papers that have been published ${ }^{1,2}$. Cavitation, he points $\stackrel{2}{\mathbb{Q}}$ out, is not exclusive to very high-velocity missiles, and $\underset{\vec{F}}{\vec{F}}$ both he and Scott have demonstrated cavitation with low-velocity missiles ${ }^{3,27}$. He makes it clear that bullets do not tumble in flight unless they have struck obstacles; drawings with exaggerated angles of yaw produced for clarity have been misinterpreted ${ }^{35}$. He points out the fallacy of using the kinetic energy deposition alone as an index of wound severity. This would be wrong because, within particular tissues and at particular sites along the wound track, the extent of cavitation can be correlated with the kinetic energy deposition at that site. The degree of cavitation, however, does not necessarily determine the severity of injury, and one cannot state $\delta$ therefore, that kinetic energy deposition alone is an index of wound severity. Clearly various tissues willo differ in their responses to given quantities of kinetic energy and some will be more resistant to injury than others.

His view that the assessment of what constitutes non- $-\widetilde{\sigma}$ viable tissue by general surgeons is very crude would ber

\section{o}


accepted. Equally accepted is his view that surgical excision alone is not the best treatment of missile wounds, but the corollary equally holds true, and few would relegate surgery to a place of minor importance in management. He points out the danger of drawing incorrect conclusions from experiments carried out on tissue simulants. Although the phenomena seen in gelatin blocks may well represent the physical events produced in living tissue, it is not correct to assume that all tissues affected in this way will be injured, either reversibly or irreversibly. He goes on to express concern that surgeons having read some ballistics literature, will overestimate the effects of injury by high-velocity missiles and may embark on treatment which is worse than the malady. It is hoped that this is an ill-founded worry, and that most surgeons will study the literature intelligently and will understand what may ensue following high-energy wounding, rather than what will follow.

It would be quite wrong, therefore, to be alarmed at apparent disagreements in recent ballistics literature. As with most medical disciplines, controversy will continue to exist, and such controversy points to a healthy atmosphere in which further research will flourish.

\section{Future Research}

A major proportion of the wound ballistics literature is concerned with the terminal ballistics of bullets encountered in civilian medical practice and the management of penetrating missile wounds in modern hospital facilities. Few papers address the problems of surgery in war, where not only is the nature of wounds different, but also where the management of casualties will be significantly influenced by the conditions prevailing in the field ${ }^{36}$. In any attempt to review briefly the contemporary wound ballistics research in support of the Army Medical Services (AMS), attention should be directed towards the management of casualties in war and away from rather unproductive arguments on, for example, the role of "shock" waves in wounding and the relative merits of soap and gelatin as tissue simulants. It is conditions in war, not those of downtown New York that must be considered. Efforts in trauma research, must therefore be directed towards the specific surgical issues that will improve the treatment of casualties under these difficult conditions, and towards the best allocation of stretched resources to provide the greatest benefit to the largest number of casualties under the special conditions of surgery in war.

Some of these "special conditions" which make the management of penetrating missile wounds different in wartime can be indicated. Firstly, most war wounds will be severely contaminated by foreign bodies, such as filthy uniform, and by bacteria.

Secondly, there may be considerable delay from the time of wounding to the time of treatment, including early treatment, such as commencement of antibiotics and resuscitation at the RAP, and primary surgery. The six hour target for the commencement of surgery is an ideal that is unlikely to be attained for most Priority $2 \frac{2}{3}$ and 3 casualties. Many may have to wait for up to $12-18$ 장 hours (or even longer) for surgery because of delays in $z$ evacuation to the Forward Surgical Complexes or $\stackrel{\mathbb{\perp}}{\complement}$ because of a decision to evacuate the Priority $2 \mathrm{~s}$ and $3 \mathrm{~s} ?$ to rear hospitals.

Thirdly, the workload in resuscitation and in the operating theatre may well be heavy, and the surgery of $\overrightarrow{\overrightarrow{\mathrm{C}}}$ penetrating wounds may be carried out by overworked, $\stackrel{9}{\circ}$ tired and inexperienced surgeons who may not always be thorough.

And lastly, there may be extended lines of evacuation causing inevitable delays.

\section{Missile Fragmentation}

It is important to recognise that most of the penetrating missile wounds seen in war will be produced $\vec{\omega}$ by fully jacketed bullets and by anti-personnel fragments.

The wound ballistics literature is dominated by work on bullets, perhaps, in part, because of the startling and $\vec{\omega}$ visually impressive effects seen within gelatin and soap blocks when hit by these high velocity missiles. Representatives of law enforcement agencies and the g: experts may debate the relative merits of penetration 0 fragmentation in this role. These questions are important for these agencies but they are not importa for the AMS. The wounds seen by the AMS in war wif not be produced by fragmenting bullets; the AK74 bullet is very strong and will not fragment. Indeed, very fey small calibre bullets will fragment although some might $\vec{\oplus}$ extrude lead from their bases. (The M113 from the M. rifle is often described as fragmenting in tissue but, fact, it will only disrupt at close range when it impacts a relatively high yaw of 3-5 degrees).

Anti-personnel fragments will, therefore, account for the majority of penetrating missile injuries. The size of $\frac{\circ}{\Phi}$ these fragments can vary considerably, but weapon $\stackrel{\varrho}{\Rightarrow}$ designers expend considerable effort to produce a $\overrightarrow{\overrightarrow{0}}$ consistent fragment size that offers the best compromise between range, velocity, probability of a hit, and terminal effectiveness. Modern pre-formed fragments weigh about $0.2 \mathrm{~g}$ with a diameter of about $2-3 \mathrm{~mm}$. Initial velocities exceed $1500 \mathrm{~m} / \mathrm{s}$ but decline rapidly with range. Large calibre $\mathrm{HE}$ shells and mortars of older design fragment into rather more variably sized missiles. The $\overparen{\mathbb{Q}}$ general pattern of injury in a large proportion of $\frac{\varrho}{\vec{F}}$ fragment casualties, wearing body armour and surviving to reach definitive surgery, will be multiple wounds to $\underline{3}$. the peripheral limbs. Most wounds will be nonperforating with injury largely confined to the wound track.

An important feature of fragment wounds is their degree of contamination by foreign bodies principally $\frac{}{0}$ clothing and skin fragments. The jagged fragment is adept at cutting uniform and transporting parts of it into $\sigma$ wounds; the bigger the fragment, the greater the $N$ 
contamination. With low energy fragments, the contamination is confined to the wound track and is usually found as a discrete plug of material. With high energy fragments wounds, typified by "large" fragments striking at or near the velocity of bullets, this pattern of contamination changes.

These large fragments are likely to lead to a greater degree of contamination because of the increase in their potential cutting area, and cloth shredded by such fragments is dispersed as small fibres which are very difficult to detect at surgery. Also, although the role of the temporary cavity in devitalisation or destruction of soft tissue may be contentious, an underestimated and generally overlooked consequence of the temporary cavity is the widespread dispersion of wound contaminants. The shredded contaminant may be widely dispersed along the wound track and may also be found some distance from the track, either in fissures within the tissue peripheral to the track or between fascial planes which may be separated by the formation of the temporary cavity. In this manner, contamination may be transported to distant sites showing no overt signs of injury. If the fragment should perforate the limb, the reduced pressure within the temporary cavity is also capable of indrawing clothing shreds from the exit wound and depositing them between fascial planes; we have demonstrated this phenomenon in our studies of wound contamination. The same principles of course, apply to bullet wounds but because of their pointed shape, bullets carry relatively little contamination into wounds.

For those suffering penetrating missile wounds to limbs, antibiotic therapy will commence at RAP or Field Ambulance. The Casualty Treatment Regimes (CTRs) specify benzyl penicillin, but for severe wound contamination, ampicillin and cloxacillin are also recommended. Priority 1 (P1) casualties will be operated upon at Forward Surgical Complexes (FSCs) but P2 and P3 casualties will normally be evacuated to Rear Surgical Complexes (RSCs) or Base Hospitals for surgery.

Many of the penetrating wounds in these latter groups will be multiple, low energy, small fragment wounds reminiscent of shot-gun pellet injuries. It is apparent, therefore, that many P2 and P3 casualties with penetrating missile wounds will not receive surgical treatment for many hours or perhaps days. The role of the antibiotic regimes must be to delay the onset of wound infection during this inevitable delay before definitive surgery may be carried out. An important area of research is the assessment of the ability of currently recommended antibiotic therapy to meet this requirement. The relative roles of antibiotic therapy, debridement and wound excision in the controlling of different types of contamination also need to be defined.

The degree and extent of contamination may vary from that described for large high energy fragment injuries to the "peppering" low energy type of injuries that may be produced by some modern anti-personnel weapons such as bomblets. Wide debridement or wound excision may not be required for some of these latter types of wounds.

Surgical debridement (laying open) of wounds is undertaken for three reasons - to reduce tissue tension, to allow the removal of contamination associated with the wound track and more distant sites such as fascial planes, and to permit adequate wound excision.

It is the degree of wound excision that is the principal target for Fackler's comments on the surgery of penetrating missile wounds ${ }^{3}$. Fackler emphasises that the formation of the temporary cavity does not necessary injure tissue adjacent to the wound track quite true, of course, for muscle - and that surgeons who operate upon such wounds with preconceived ideas of the role of the cavitation effect may well be too radical in wound excision and may remove recoverable and viable tissue.

Now, if the sole purpose of wound excision was to remove dead tissue and non-viable tissue, then Fackler would be right to debate the viability of "stretched" tissue and to question the criteria for wound excision. The authors, however, believe that excision of wab wounds has an additional purpose, namely the removef of the contamination, and if potentially viable tissue has to be sacrificed to achieve this, then such a sacrifice is justified. In this context, questions on the critica $\Phi$ delineation of viable and non-viable tissue becom academic.

Those working in the field of wound ballistics, and who are primarily interested in the management of war wounds should study the relative importance o甲 antibiotics, debridement and wound excision on the onset of wound sepsis and systemic infection over the time scales realistically likely to be encountered in war. The object of this research should be to minimise the surgical load involved in the treatment of large numbers of P2 and P3 casualties without increasing the number of wounds which become infected, or reducing the numbers of wounds which heal well.

\section{Conclusion}

Future study should address specific pertinent questions.

The benefits which would accrue from the use of antibiotics forward of the RAP must be assessed, and it must be determined if these would outweigh the cost and logistic problems of such use.

It must be established for how long the current antibiotic policy will delay the onset of serious wound infection in the different patterns of wound contamination described in this article.

The necessity for time-intensive procedures, such as formal wound excision for all wounds must be studied to find out if adequate debridement and mechanical irrigation (using for example, hydrogen peroxide, povidone iodine or eusol) will control contamination in 
selected wounds. Indeed, an attempt should be made to identify any type of penetrating missile wounds where management by antibiotics and dressings alone might suffice.

The wound infection experiments by Dahlgren et al represent a beginning in this field ${ }^{31,32}$. Wound infection has been the principal adversary of Military Surgeons for generations. Much more needs to be done so that Military Surgeons will be ready, should the need arise, to provide the best possible care for the soldier wounded on the modern battlefield.

\section{Acknowledgement}

The authors wish to express their thanks to Mr Leslie Payne, Honorary Ballistics Archivist to the Royal Army Medical Corps, for his invaluable help in tracing source material and for access to his Ballistics library.

\section{REFERENCES}

1. Barach E, Tomlanovich M and Nowak R. A Pathophysiologic Examination of the Wounding Mechanisms of Firearms: Part I. J Trauma 1986; 26: 225-235.

2. Barach E, Tomlanovich $M$ and Nowak R. A Pathophysiologic Examination of the Wounding Mechanisms of Firearms: Part II. J Trauma 1986; 26: 374383.

3. FACKLER M L. What's wrong with the wound ballistics literature, and why? Letterman Army Institute of Research Report No 239: 1987. California.

4. FACKLER M L. and LINDSEY D. Letter to the Editor. $J$ Trauma 1986; 26: 1158-1159.

5. LINDSEY D. The Idolatry of Velocity, or Lies, Damn Lies, and Ballistics. J Trauma 1980; 20:1068-1069.

6. Keynes G. The Apologies and Treatise of Ambroise Pare (Taken from Th Johnson's translations of 1634 and 1665). 1957 Chicago: University of Chicago Press.

7. Hunter J. A Treatise on the Blood, Inflammation and Gunshot Wounds, 1812 Vol 2. London: E Cox.

8. Huguier M. Plaies d'armes a feu. Bulletin de l'Academie Nationale de Medicine 1848; 14: 7-112.

9. LoNgmore T, Surgeon General. Gunshot Injuries: Their history, characteristics features, complications, and general treatment. 1877 London: Longmans, Green, and Co.

10. Otis G A. The Medical and Surgical History of the War of Rebellion (1861-65), Vol II of Part I - Surgical Volume. (Second Issue). Washington 1875: Government Printing Office.

11. Otis G A. The Medical and Surgical History of the War of Rebellion, Part II - Vol II. Surgical History (Second Issue) Washington 1876: Government Printing Office.

12. Otis G A and Huntingdon D L. The Medical and Surgical History of the War of Rebellion. Part III - Vol II. Surgical History. (Second Issue). Washington: 1883 Government Printing Office.

13. KOCHER T. Ueber die Sprengwirkung der Modernen Kleingewehr-Geschosse. Correspondenz-Blatt fur Schweizer Aerzte 1875; Vol V: 3-7.
14. Horsley V. The Destructive Effects of Projectiles. Proceedings of the Royal Institution of Great Britain 1894; XIV: 228-238.

15. STEVENSON W F. Wounds in War: The Mechanism of Their Production and Their Treatment. London 1897: Longmans, Green, and Co.

16. WoOdruFF $\mathrm{C}$ E. The causes of the explosive effects of modern small calibre bullets. New York Medical Journal 1898; 67: 593-601.

17. Callender G R and French R W. Wound ballistics - $\overrightarrow{\vec{D}}$ Studies in the Mechanism of Wound Production by Rifle Bullets. The Military Surgeon 1935; 77: 177-201.

18. BlaCK A N, BuRns B D and ZuCKerman S. An Experimental study of the Wounding Mechanism of High Velocity Missiles. Lancet 1941; 2: 872-874.

19. HaRveY E N, et al. Mechanism of Wounding. War \& Medicine 1945; 8:91-104.

20. Hopkinson D A W. and Watts J C. Studies in Experimental Missile Injuries of Skeletal Muscle. Proc $R$ Soc Med 1963; 56: 461-468.

21. OWen-Smith M S and Matheson J M. Successful Prophylaxis of Gas Gangrene in the High Velocity Wound in Sheep. BrJ Surg 1968; 5: 36-39.

22. OWEn-SMith M S. The Successful Prophylaxis of Gas Gangrene. M S Thesis 1971: University of London.

23. Hopkinson D A W. The use of Giemsa stain to Demonstrate Histologically the Extent of Altereq Striated Muscle Around Bullet Wounds. $J$ Path and Ba震 1964; 54: 63-69.

24. Thoresby F P and Darlow $H$ M. The Mechanisms o Primary Infection of Bullet Wounds. Br J Surg 1967; 58 359-361.

25. ThORESBy F P and MATHESON J M. Gas Gangrene of th High Velocity Missile Wound. J R Army Med Corps $196 \%$ 113: 31-39.

26. Thoresby F P and Watts J C. Gas Gangrene of the High Velocity Missile Wound. Br J Surg 1967; 54: 25-29.

27. ScotT R. Projectile Trauma: An Enquiry into Bull Wounds. M Ch Thesis 1976: Oxford University.

28. Krauss M. Studies in Wound Ballistics: Temporary Cavity Effects in Soft Tissue. Milit Med 1957; 121: 221231.

29. BERLIN R H. Missile Injury to Live Muscle Tissue. Current Principles of Surgical Treatment in Reference to New Experimental Evidence. Acta Chir Scand 1977; Suppl 480.

30. BERLIN R H, et al. Local Effects of Assault Rifle Bullets in Live Tissues. Acta Chir Scand 1976; Suppl 459.

31. Dahlgren B. et al. Bacteriological findings in the first twelve hours following experimental missile trauma. Acta Chir Scand 1981; 147: 513-518.

32. DahlgRen B, et al. Local effects of antibacterial therapy (Benzyl-Penicillin) on missile wound infection rate and tissue devitalisation when debridement is delayed for twelve hours. Acta Chir Scand 1982; Suppl 508: 271-279.

33. COOPER G J, et al. Casualties from Terrorist Bombings. $J$ Trauma 1983; 23: 955-967.

34. SwaN K G. Missile Injuries: Wound Ballistics and Principles of Management. Milit Med 1987; 152: 29-34.

35. Hopkinson D A W and MARShall T K. Firearm Injuries. Br J Surg 1967: 54: 344.

36. JACKSON D S, et al. The Falklands War: Army Field Surgical Experience. Ann R Coll Surg Engl 1983; 65: 281285 . 